\title{
Prevalence of cardiovascular disease risk factors among pharmacy students from Wroclaw Medical University (Poland)
}

\author{
Rafał llow $w^{1, A-D}$, Dorota Różańska 2, A, C, D, Bożena Regulska-llow2, B, E,F \\ 1 Department of Food Science and Dietetics, Wroclaw Medical University, Poland \\ 2 Department of Dietetics, Wroclaw Medical University, Poland \\ A - research concept and design; $B$ - collection and/or assembly of data; $C$ - data analysis and interpretation; \\ $D$ - writing the article; $E$ - critical revision of the article; $F$ - final approval of article
}

Address for correspondence

Dorota Różańska

E-mail:dorota.rozanska@umed.wroc.pl

Funding sources

None declared

Conflict of interest

None declared

Received on July 01,2015

Revised on December 26, 2015

Accepted on January 19, 2016

\begin{abstract}
Background. Atherosclerotic processes begin in childhood and their development worsens during adolescence. Early prevention of CVD risk factors may have an important impact on the future health of young people. It can be also helpful in reducing the costs of treating CVD later in life.
\end{abstract}

Objectives. The aim of this study was to assess the prevalence of selected cardiovascular disease risk factors among pharmacy students.

Material and methods. The study group consisted of 1,168 pharmacy students (892 women and 276 men) from Wroclaw Medical University. The average age was 22.9 years among women and 23.2 years among men. This cross-sectional study was conducted between 2004-2012.

Results. 27.5\% of men and 7.1\% of women were found to be overweight, while visceral obesity was found in $15.2 \%$ and in $10.1 \%$ of students, respectively. Hypertension was diagnosed in 27.2\% of men and in 7.8\% of women. Low physical activity was declared by $41.9 \%$ of women and by $31.9 \%$ of men. There were $22.1 \%$ of men and $10 \%$ of women who were current smokers. The majority of the study group did not consume enough fruits and vegetables (women 61.8\%, men 75\%). Body mass index (BMI) was positively associated with waist and hip measurements, waist-to-hip ratio (WHR) and body fat percentage, while blood pressure was positively associated with BMI and waist circumference. It was found that men with high physical activity had lower BMIs, body fat percentage, waist and hip circumferences, WHR, diastolic blood pressure and heart rate than those who declared low physical activity. Comparing women with high physical activity to those with low physical activity, only lower heart rate was observed.

Conclusions. A higher prevalence of cardiovascular risk factors was found more often among men than women. Preventive actions which promote proper nutrition, more physical activity, smoking cessation and regular blood pressure checks and lipid profile tests should be implemented for the students.

Key words: risk factors, cardiovascular disease, lifestyle, hypertension, university students

DOI

10.17219/acem/61439

\section{Copyright}

Copyright by Author(s)

This is an article distributed under the terms of the

Creative Commons Attribution Non-Commercial License

(http://creativecommons.org/licenses/by-nc-nd/4.0/) 
The prevalence of cardiovascular diseases (CVD) is notably associated with lifestyle factors such as smoking, unhealthy diet and low physical activity. Other risk factors for CVD, e.g. excessive body weight, high blood pressure, dyslipidemia and high blood glucose level, can also be related to lifestyle. ${ }^{1}$ According to the Global Burden of Diseases, Injuries, and Risk Factors Study 2010 (GBD 2010), deaths caused by all non-communicable diseases increased by 30\% between 1990 and 2010. Deaths caused by cardiovascular and circulatory diseases increased by $31.2 \%$ during those years, while deaths caused by diabetes, urogenital, blood and endocrine diseases increased by $76.5 \%$. In 2010, global CVD mortality among women aged 15-49 years was $10.7 \%$ and among men $12.8 \%{ }^{2}$ According to the World Health Organization (WHO), the highest mortality rates of CVDs in 2008 were found in Estonia, followed by Hungary and Croatia. The mortality rates of CVDs in Poland placed $7^{\text {th }}$ among the countries which were taken into account. ${ }^{1}$

A healthy lifestyle is one of the major factors in CVD prevention, a fact which is emphasized by experts from the European Society of Cardiology (ESC). ${ }^{3}$ Preventive actions should begin even before birth by educating young parents, and should subsequently be continued at pre-school and school age. Therefore, actions aimed at preventing CVD should be part of everyday life beginning with childhood and they should be continued for adolescents, adults and the elderly. ${ }^{3}$ Obesity in the first years of life increased the risk of obesity in adulthood and the development of metabolic syndrome and type 2 diabetes in adolescence and adulthood. ${ }^{4}$ Juonala et al. observed that obese adults who were overweight in their childhood had an increased risk of dyslipidemia, hypertension, type 2 diabetes and carotid-artery atherosclerosis. ${ }^{5}$ Other authors also suggested that the development of atherosclerosis may be increased by the occurrence of CVD risk factors in early life. ${ }^{6}$ Therefore, early prevention of risk factors may have a significant influence on CVD development in the future. ${ }^{7}$

The aim of this study was to evaluate the prevalence of selected cardiovascular disease risk factors among pharmacy students from Wroclaw Medical University.

\section{Material and methods}

\section{Study group}

The study group consisted of 1,168 pharmacy students (892 women and 276 men) from Wroclaw Medical University. This cross-sectional study was carried out between 2004 and 2012. All students who were $4^{\text {th }}$-year pharmacy students at the time agreed to participate in the study and were recruited into the study. Women who were pregnant were excluded from the study. During the study period, the following number of students were re- cruited: 154 people in 2004; 141 in 2005; 127 in 2006; 130 in 2007; 124 in 2008; 125 in 2009; 114 in 2010; 139 in 2011; and 114 in 2012. None of the participants declared that they were taking any medications for the treatment of chronic diseases. The average age was 22.9 years among women and 23.2 years among men. The demographics of the study group are presented in Table 1 . The study group was asked to complete questionnaires, which included 46 questions about their nutritional habits and lifestyle.

\section{Measurements}

To assess the risk factors for CVD among the study group, anthropometrical parameters such as height (rounded to $1 \mathrm{~cm}$ ), weight (rounded to $1 \mathrm{~kg}$ ) and waist and hip circumference (rounded to $1 \mathrm{~cm}$ ) were measured. Weight was measured using an electronic personal scale (Beurer $\mathrm{GmbH}$, Germany) and waist and hip circumferences using non-stretch measuring tape. Based on these anthropometric measurements, body mass index (BMI) and waist-to-hip ratio (WHR) were calculated. BMI classification from the WHO was used. ${ }^{8}$ Abdominal obesity was assessed using WHR and waist circumference. The abnormal values for WHR among women and men were $\geq 0.8$ and $\geq 0.95$, respectively, and those for waist circumference were $\geq 80 \mathrm{~cm}$ and $\geq 94 \mathrm{~cm}$, respectively. ${ }^{9,10}$ The percentage of body fat was measured using a BF306 Body Fat Monitor (OMRON, Japan). The measurement of body fat percentage was based on electrical resistance and personal data: gender, age, height and weight. Blood pressure was measured using an M6 Blood Pressure Monitor (OMRON, Japan) with a size 3 arm cuff. Measurements were performed twice during 2 visits ( 4 measurements in total) 1 week apart. Hypertension was diagnosed when systolic blood pressure was $\geq 140 \mathrm{~mm} \mathrm{Hg}$ and/or diastolic blood pressure was $\geq 90 \mathrm{~mm} \mathrm{Hg} .{ }^{11}$

\section{Statistical analysis}

Continuous variables were summarized by averages, standard deviations (SD) and medians. A non-parametric Mann-Whitney U test was used to compare linear variables and a $X^{2}$ test was used to compare categorical variables. A linear Pearson's correlation test was performed to determine the relationships between data. The criterion for statistical significance was set at the p-value $<0.05$. Statistical analyses were made using STATISTICA v. 10.0 PL software (StatSoft Inc., USA).

\section{Results}

Anthropometrical parameters, body fat percentage and blood pressure were measured among the study group (Table 1). It was found that height, weight, waist and hip circumferences, BMI, WHR and systolic blood pressure 
Table 1. Characteristic of the study group $(n=1168)$

\begin{tabular}{|c|c|c|c|c|c|}
\hline \multirow{2}{*}{ Parameter } & \multicolumn{2}{|c|}{ Women $(n=892)$} & \multicolumn{2}{|c|}{ Men $(n=276)$} & \multirow{2}{*}{$\begin{array}{c}\text { Women vs men* } \\
\text { p-value }\end{array}$} \\
\hline & mean $\pm S D$ & median & mean $\pm S D$ & median & \\
\hline Age (year) & $22.9 \pm 1.4$ & 23.0 & $23.2 \pm 1.9$ & 23.0 & ns \\
\hline Height (cm) & $166.8 \pm 6.0$ & 167.0 & $180.0 \pm 6.3$ & 180.0 & $<0.0001$ \\
\hline Weight (kg) & $57.7 \pm 8.7$ & 56.0 & $76.3 \pm 11.3$ & 76.0 & $<0.0001$ \\
\hline BMI $\left(\mathrm{kg} / \mathrm{m}^{2}\right)$ & $20.7 \pm 2.7$ & 20.3 & $23.5 \pm 3.2$ & 23.0 & $<0.0001$ \\
\hline Waist (cm) & $70.7 \pm 7.0$ & 69.0 & $85.3 \pm 8.5$ & 85.0 & $<0.0001$ \\
\hline Hip (cm) & $95.2 \pm 6.4$ & 95.0 & $99.2 \pm 6.5$ & 99.0 & $<0.0001$ \\
\hline WHR & $0.74 \pm 0.05$ & 0.74 & $0.86 \pm 0.05$ & 0.86 & $<0.0001$ \\
\hline Body fat (\%) & $27.8 \pm 5.4$ & 27.6 & $18.8 \pm 5.9$ & 18.5 & $<0.0001$ \\
\hline $\mathrm{SPB}(\mathrm{mm} \mathrm{Hg})$ & $122.0 \pm 11.1$ & 122.0 & $134.4 \pm 12.9$ & 133.0 & $<0.0001$ \\
\hline $\mathrm{DBP}(\mathrm{mm} \mathrm{Hg})$ & $76.2 \pm 8.3$ & 76.0 & $75.5 \pm 8.7$ & 75.0 & ns \\
\hline Heart rate & $80.1 \pm 12.9$ & 78.0 & $76.3 \pm 15.8$ & 74.0 & $<0.0001$ \\
\hline
\end{tabular}

BMI - body mass index; WHR - waist to hip ratio; SBP - systolic blood pressure; DBP - diastolic blood pressure; SD - standard deviation; * - U Mann-Whitney test; ns - no significant differences.

(SBP) were significantly higher among men than among women. The opposite relationship was observed in percentage of body fat and pulse.

The prevalence of selected risk factors for CVD is presented in Table 2. Although the average BMI among both men and women indicated normal body weight, there were $27.5 \%$ of men and $7.1 \%$ of women with excessive body weight ( $p<0.0001)$. However, a notable part of the study group, especially women (17.9\%), were underweight. Visceral obesity was observed significantly more often among men than women (15.2\% vs $10.1 \%)$. Hypertension occurred almost 4-fold more frequently among men than women.

Students were asked to qualify their physical activity by choosing 1 of the 5 following answers: no physical activity; 20-60 min once a week; $20-60$ min 2-3 times a week; 20-60 min 4-6 times a week; or 20-60 min every day. Low physical activity, as defined by options 1 and 2, was declared significantly more often by women than by men (41.9\% vs $31.9 \%)$.

Significantly more men than women were current or former smokers (36.6\% vs $19.4 \%$ ). Almost $50 \%$ of the study group had never measured their blood cholesterol level and $27.9 \%$ had not measured it in the year prior to the study. About $53 \%$ of women and $50 \%$ of men had not measured their blood pressure in the month prior to the study. A history of CVD in the family was declared by $34.9 \%$ of women and by $32.6 \%$ of men.

The majority of the study group did not consume enough fruits and vegetables. Intake of less than the recommended 5 servings of these foods per day overall was declared by about $62 \%$ of women and $75 \%$ of men. However, when taking into account the recommendation to consume at least 3 servings of vegetables and at least 2 servings of fruit daily, the insufficient intake of these foods was found in about $75 \%$ of women and $84 \%$ of men (Table 2).

Table 3 summarizes the correlations between BMI, waist circumference, WHR, body fat percentage and other parameters. BMI correlated stronger with waist circumference than with WHR in both men and women. A strong correlation was also found between BMI and body fat percentage. Larger hip circumference, higher WHR and higher body fat percentage were observed with increasing waist circumference. Correlations between blood pressure and anthropometric variables were weak or statistically insignificant.

The comparison between participants with excessive body weight and those with BMI $<25 \mathrm{~kg} / \mathrm{m}^{2}$ is shown in Table 4. It was observed that women with BMI $\geq 25 \mathrm{~kg} / \mathrm{m}^{2}$ had significantly higher SBP, DBP, heart rate, body fat percentage, waist and hip circumferences and WHR compared to those with BMI $<25 \mathrm{~kg} / \mathrm{m}^{2}$. Similar results were obtained in the group of men, with the exception of SBP and DBP, where no significant differences were found.

It was observed that women with abdominal obesity had significantly higher BMI, SBP, DBP, heart rate, body fat percentage, hip circumference and WHR, compared 
Table 2. Prevalence of selected risk factors in the study group $(n=1168)$

\begin{tabular}{|c|c|c|c|c|c|}
\hline \multirow{2}{*}{ Parameter } & \multicolumn{2}{|c|}{ Women $(W) n=892$} & \multicolumn{2}{|c|}{ Men $(M) n=276$} & \multirow{2}{*}{$\frac{\text { Wvs } M^{*}}{p \text {-value }}$} \\
\hline & $\mathrm{n}$ & $\%$ & $\mathrm{n}$ & $\%$ & \\
\hline $\mathrm{BMI}<18.5\left(\mathrm{~kg} / \mathrm{m}^{2}\right)$ & 161 & 17.9 & 9 & 3.3 & $<0.0001$ \\
\hline BMI $18.5-24,9\left(\mathrm{~kg} / \mathrm{m}^{2}\right)$ & 668 & 74.9 & 191 & 69.2 & ns \\
\hline $\mathrm{BMI} \geq 25\left(\mathrm{~kg} / \mathrm{m}^{2}\right)$ & 63 & 7.1 & 76 & 27.5 & $<0.0001$ \\
\hline Overweight & 53 & 5.9 & 66 & 23.9 & $<0.0001$ \\
\hline Obesity & 10 & 1.1 & 10 & 3.6 & 0.0113 \\
\hline $\begin{array}{l}\text { Abdominal obesity by } W C \\
(W \geq 80 \mathrm{~cm} ; M \geq 94 \mathrm{~cm})\end{array}$ & 90 & 10.1 & 42 & 15.2 & 0.0187 \\
\hline $\begin{array}{l}\text { Abdominal obesity by WHR } \\
(W \geq 0.8 ; M \geq 0.95)\end{array}$ & 120 & 13.5 & 13 & 4.7 & 0.0001 \\
\hline Hypertension (yes) & 70 & 7.8 & 75 & 27.2 & $<0.0001$ \\
\hline Current smokers & 89 & 10.0 & 61 & 22.1 & $<0.0001$ \\
\hline Former smokers & 84 & 9.4 & 40 & 14.5 & 0.0168 \\
\hline Current + former smokers & 173 & 19.4 & 101 & 36.6 & $<0.0001$ \\
\hline Low physical activity & 374 & 41.9 & 88 & 31.9 & 0.0029 \\
\hline $\begin{array}{l}\text { Prevalence of CVD in family } \\
\text { (yes) }\end{array}$ & 311 & 34.9 & 90 & 32.6 & ns \\
\hline $\begin{array}{l}\text { Low vegetable intake } \\
(<3 \text { portion/day) }\end{array}$ & 623 & 69.8 & 218 & 79.0 & 0.0031 \\
\hline $\begin{array}{l}\text { Low fruit intake } \\
(<2 \text { portion/day })\end{array}$ & 280 & 31.4 & 133 & 48.2 & $<0.0001$ \\
\hline $\begin{array}{l}\text { Low fruit and vegetable } \\
\text { intake } \\
\text { (<5 portion/day) }\end{array}$ & 551 & 61.8 & 207 & 75.0 & 0.0001 \\
\hline $\begin{array}{l}\text { Vegetables }<3 \text { portions AND } \\
\text { fruits }<2 \text { portions }\end{array}$ & 671 & 75.2 & 231 & 83.7 & 0.0034 \\
\hline $\begin{array}{l}\text { Was the cholesterol } \\
\text { measured last year? } \\
\text { (no + don't remember } \\
\text { + never) }\end{array}$ & 821 & 92.0 & 254 & 92.0 & ns \\
\hline Not measured last year & 249 & 27.9 & 77 & 27.9 & ns \\
\hline Never & 430 & 48.2 & 131 & 47.5 & ns \\
\hline Don't remember & 142 & 15.9 & 46 & 16.7 & ns \\
\hline $\begin{array}{l}\text { Was the BP measured } \\
\text { last month? (no + don't } \\
\text { remember) }\end{array}$ & 487 & 54.6 & 145 & 52.5 & ns \\
\hline Not measured last month & 470 & 52.7 & 137 & 49.6 & ns \\
\hline Don't remember & 17 & 1.9 & 8 & 2.9 & ns \\
\hline
\end{tabular}

W - women; M - men; BMI - body mass index; WC - waist circumference; WHR - waist to hip ratio; CVD - cardiovascular diseases; $B P$ - blood pressure; ${ }^{*}-X^{2}$ test; Ns - no significant differences. to those with waist circumference $<80 \mathrm{~cm}$ (Table 5). Similar results appeared among the men, except SBP, where no significant differences were found.

In both groups, participants with hypertension had higher BMI than those with normal blood pressure (Table 6). Women with hypertension also had larger hip circumferences than those without hypertension. Among men with hypertension compared to those without, higher waist circumference and WHR was observed.

Table 7 presents the comparison between participants who declared low and high physical activity. It was found that men with high physical activity had lower BMI, body fat percentage, waist and hip circumferences, WHR, DBP and heart rate than those who declared low physical activity. In the group of women, only lower heart rate was observed among those with high physical activity compared to those with low physical activity.

\section{Discussion}

Atherosclerotic processes begin in childhood and their development proceeds during adolescence. Early prevention of CVD risk factors might have an important impact on future health. It can be also helpful in reducing the costs of treating CVD later in life. Regular calculation of BMI and measurement of blood pressure along with screening and counseling for nutritional problems and eating disorders, physical activity and smoking cessation are recommended as prevention and treatment of CVD. ${ }^{7}$

Obesity is one of the major risk factors for CVD and it is a growing worldwide problem. It is related to other risk factors and may cause metabolic disorders. ${ }^{1}$ In the Bogalusa Heart Study, the authors concluded that excessive body weight in adolescence and remaining in young adulthood has a strong impact on CVD risk factors, a scenario which requires primary prevention in early life. ${ }^{12}$ In the previous study conducted on pharmacy students between 1998 and 2003, the authors observed a slightly lower prevalence of excess weight and obesity than in the present study. ${ }^{13}$ Results similar to those obtained from students from Wrocław 
Table 3. Pearson correlation between selected parameters in the study group $(n=1168)$

\begin{tabular}{|c|c|c|c|c|}
\hline \multirow{2}{*}{ Variables } & \multicolumn{2}{|c|}{ Women $(\mathrm{n}=892)$} & \multicolumn{2}{|c|}{ Men $(n=276)$} \\
\hline & r & $p$-value & r & $\mathrm{p}$-value \\
\hline \multicolumn{5}{|c|}{ BMI } \\
\hline Waist & 0.7683 & 0.000 & 0.8283 & 0.000 \\
\hline Hip & 0.8312 & 0.000 & 0.8288 & 0.000 \\
\hline WHR & 0.2632 & 0.000 & 0.4527 & 0.000 \\
\hline Body fat percentage & 0.6995 & 0.000 & 0.7278 & 0.000 \\
\hline SBP & 0.1878 & 0.000 & 0.1722 & 0.004 \\
\hline DBP & 0.1810 & 0.000 & 0.2086 & 0.000 \\
\hline Heart rate & 0.0049 & 0.883 & 0.0355 & 0.557 \\
\hline \multicolumn{5}{|c|}{ Waist } \\
\hline Hip & 0.7262 & 0.000 & 0.8029 & 0.000 \\
\hline WHR & 0.7080 & 0.000 & 0.7679 & 0.000 \\
\hline Body fat percentage & 0.5781 & 0.000 & 0.6982 & 0.000 \\
\hline SBP & 0.1304 & 0.000 & 0.1732 & 0.004 \\
\hline DBP & 0.1103 & 0.001 & 0.2326 & 0.000 \\
\hline Heart rate & 0.0577 & 0.085 & 0.0402 & 0.506 \\
\hline \multicolumn{5}{|c|}{ WHR } \\
\hline Hip & 0.0317 & 0.344 & 0.2371 & 0.000 \\
\hline Body fat percentage & 0.1659 & 0.000 & 0.4071 & 0.000 \\
\hline SBP & -0.0036 & 0.915 & 0.1484 & 0.014 \\
\hline DBP & -0.0144 & 0.669 & 0.1821 & 0.002 \\
\hline Heart rate & 0.0401 & 0.232 & 0.0025 & 0.967 \\
\hline \multicolumn{5}{|c|}{ Body fat percentage } \\
\hline SBP & 0.0850 & 0.011 & 0.0976 & 0.106 \\
\hline DBP & 0.1548 & 0.000 & 0.2278 & 0.000 \\
\hline Heart rate & 0.0537 & 0.109 & 0.0876 & 0.147 \\
\hline
\end{tabular}

r - correlation coefficient; BMI - body mass index; WHR - waist to hip ratio; SBP - systolic blood pressure; DBP - diastolic blood pressure.

were also observed by other authors assessing the occurrence of excessive weight and obesity among students from other Polish cities. ${ }^{14,15}$ In the WOBASZ study (National Multicenter Health Survey in Poland), BMI $\geq 25$ $\mathrm{kg} / \mathrm{m}^{2}$ occurred more frequently among participants aged 20-34 than among the examined students from Wrocław (men: $41 \%$ vs $27.5 \%$; women: $20 \%$ vs $7.1 \%) .{ }^{16}$ A higher prevalence of excessive body weight in the group of students,
Table 4. Comparison between average values of selected parameters among participants with $\mathrm{BMl}<25 \mathrm{~kg} / \mathrm{m}^{2}$ and with $\mathrm{BMI} \geq 25 \mathrm{~kg} / \mathrm{m}^{2}$

\begin{tabular}{|l|c|c|c|c|}
\hline Parameters & \multicolumn{2}{|c|}{ Women $(\mathrm{n}=892)$} & \multicolumn{2}{c|}{ Men $(\mathrm{n}=276)$} \\
\hline \multicolumn{1}{|c|}{ BMI } & $<25 \mathrm{~kg} / \mathrm{m}^{2}$ & $\geq 25 \mathrm{~kg} / \mathrm{m}^{2}$ & $<25 \mathrm{~kg} / \mathrm{m}^{2}$ & $\geq 25 \mathrm{~kg} / \mathrm{m}^{2}$ \\
\hline Waist (cm) & 69.6 & $85.4^{\mathrm{a}}$ & 82.0 & $94.1^{\mathrm{a}}$ \\
\hline Hip (cm) & 94.2 & $109.1^{\mathrm{a}}$ & 96.7 & $105.9^{\mathrm{a}}$ \\
\hline WHR & 0.74 & $0.78^{\mathrm{a}}$ & 0.85 & $0.89^{\mathrm{a}}$ \\
\hline Body fat (\%) & 27.1 & $37.6^{\mathrm{a}}$ & 16.7 & $24.3^{\mathrm{a}}$ \\
\hline SBP (mm Hg) & 121.4 & $129.9^{\mathrm{a}}$ & 133.6 & 136.5 \\
\hline DBP (mm Hg) & 75.7 & $82.8^{\mathrm{a}}$ & 74.9 & 77.3 \\
\hline Heart rate & 79.8 & $83.3^{\mathrm{a}}$ & 75.5 & $78.3^{\mathrm{a}}$ \\
\hline
\end{tabular}

BMI - body mass index; WHR - waist to hip ratio; SBP - systolic blood pressure; DBP - diastolic blood pressure; ${ }^{\mathrm{a}}$ - significant differences $(\mathrm{p}<0.5)$ between participants with $\mathrm{BMl}<25 \mathrm{~kg} / \mathrm{m}^{2}$ and with $\mathrm{BMI} \geq 25 \mathrm{~kg} / \mathrm{m}^{2}$

Table 5. Comparison between average values of selected parameters among participants with abdominal obesity and with proper waist circumference

\begin{tabular}{|l|c|c|c|c|}
\hline \multicolumn{1}{|c|}{ Parameters } & \multicolumn{2}{|c|}{ Women $(\mathrm{n}=892)$} & \multicolumn{2}{c|}{ Men $(\mathrm{n}=276)$} \\
\hline $\begin{array}{c}\text { waist } \\
\text { circumference }\end{array}$ & $<80 \mathrm{~cm}$ & $\geq 80 \mathrm{~cm}$ & $<94 \mathrm{~cm}$ & $\geq 94 \mathrm{~cm}$ \\
\hline Hip (cm) & 94.1 & $105.7^{\mathrm{a}}$ & 97.7 & $107.7^{\mathrm{a}}$ \\
\hline WHR & 0.73 & $0.81^{\mathrm{a}}$ & 0.85 & $0.92^{\mathrm{a}}$ \\
\hline BMI $\left(\mathrm{kg} / \mathrm{m}^{2}\right)$ & 20.2 & $25.3^{\mathrm{a}}$ & 22.7 & $28.2^{\mathrm{a}}$ \\
\hline Body fat (\%) & 27.1 & $34.6^{\mathrm{a}}$ & 17.4 & $26.5^{\mathrm{a}}$ \\
\hline SBP $(\mathrm{mm} \mathrm{Hg})$ & 121.4 & $128.0^{\mathrm{a}}$ & 134.1 & $135.8^{\mathrm{a}}$ \\
\hline DBP $(\mathrm{mm} \mathrm{Hg})$ & 75.7 & $80.3^{\mathrm{a}}$ & 74.9 & $79.2^{\mathrm{a}}$ \\
\hline Heart rate & 79.7 & $83.1^{\mathrm{a}}$ & 75.6 & $80.0^{\mathrm{a}}$ \\
\hline
\end{tabular}

WHR - waist to hip ratio; $\mathrm{BMI}$ - body mass index; SBP - systolic blood pressure; DBP - diastolic blood pressure; ${ }^{a}$ - significant differences $(p<0.5)$ between participants with abdominal obesity and with proper waist circumference.

compared to the current study, was observed also in Greece (men: 39.5\%; women: 23.3\%) and Lebanon (men: 50\%; women: $16.8 \%){ }^{17,18}$

Actions aimed at preventing hypertension should be addressed to those who do not have the disease as well as to those who already have high BP. The development of hypertension can be prevented in particular by changing the patient's lifestyle. According to the recommendations of the Polish Society of Hypertension, annual BP screening should be performed on all adults, regardless of the previous measurement. ${ }^{11}$ The WHO emphasizes 
Table 6. Comparison between average values of selected parameters among participants with and without hypertension

\begin{tabular}{|l|c|c|c|c|}
\hline \multicolumn{1}{|c|}{ Parameters } & \multicolumn{2}{|c|}{ Women $(\mathrm{n}=892)$} & \multicolumn{2}{c|}{ Men $(\mathrm{n}=276)$} \\
\hline Hypertension & yes & no & yes & no \\
\hline Waist $(\mathrm{cm})$ & 73.8 & 70.5 & 88.0 & $84.3^{\mathrm{a}}$ \\
\hline Hip (cm) & 97.8 & $95.0^{\mathrm{a}}$ & 100.5 & 98.7 \\
\hline WHR & 0.75 & 0.74 & 0.88 & $0.85^{\mathrm{a}}$ \\
\hline BMl (kg/m²) & 21.8 & $20.6^{\mathrm{a}}$ & 24.4 & $23.2^{\mathrm{a}}$ \\
\hline Body fat (\%) & 29.1 & 27.7 & 19.7 & 18.4 \\
\hline
\end{tabular}

WHR - waist to hip ratio; $\mathrm{BMI}$ - body mass index; ${ }^{\mathrm{a}}$ - significant differences $(p<0.5)$ between participants with and without hypertension.

Table 7. Comparison between average values of selected parameters among participants with low and high physical activity

\begin{tabular}{|l|c|c|c|c|}
\hline \multicolumn{1}{|c|}{ Parameters } & \multicolumn{2}{|c|}{ Women $(\mathrm{n}=892)$} & \multicolumn{2}{|c|}{ Men $(\mathrm{n}=276)$} \\
\hline $\begin{array}{c}\text { Low physical } \\
\text { activity }\end{array}$ & no & yes & no & yes \\
\hline Waist (cm) & 70.3 & 71.4 & 84.1 & $87.9^{\mathrm{a}}$ \\
\hline Hip (cm) & 95.0 & 95.6 & 98.6 & $100.6^{\mathrm{a}}$ \\
\hline WHR & 0.74 & 0.75 & 0.85 & $0.87^{\mathrm{a}}$ \\
\hline BMI (kg/m $)^{2}$ & 20.6 & 20.8 & 23.1 & $24.4^{\mathrm{a}}$ \\
\hline Body fat (\%) & 27.6 & 28.2 & 17.5 & $21.6^{\mathrm{a}}$ \\
\hline SBP (mm Hg) & 121.5 & 122.8 & 134.8 & 133.5 \\
\hline DBP (mm Hg) & 75.9 & 76.6 & 74.6 & $77.5^{\mathrm{a}}$ \\
\hline Heart rate & 78.7 & $81.9^{\mathrm{a}}$ & 73.7 & $81.8^{\mathrm{a}}$ \\
\hline
\end{tabular}

WHR - waist to hip ratio; BMI - body mass index; SBP - systolic blood pressure; DBP - diastolic blood pressure; ${ }^{a}$ - significant differences $(p<0.5)$ between participants with low and high physical activity.

that hypertension is a major risk factor not only for myocardial infarction and stroke, but also renal impairment, heart failure and blindness. ${ }^{1}$ For the prevention of strokes and heart attacks, hypertension should be detected and treated early. ${ }^{1}$ In the present study, more than half of the study group did not have their blood pressure checked during the previous month prior to the study. The prevalence of hypertension in the study group was similar to that observed in the pharmacy students between 1998 and $2003 .{ }^{13}$ In the WOBASZ study, the occurrence of hypertension in the group aged 20-34 was lower than that observed in this study. ${ }^{16}$ However, hypertension, as in the current study, was diagnosed more frequently among men than among women. ${ }^{16}$ Krzych et al. also found that the prevalence of hypertension was higher among young men than women (20.9\% vs 9.9\%). ${ }^{19}$ A similar relationship was observed among Greek students (13.3\% vs $6.7 \%$ ); however, the prevalence of hypertension was lower than among Polish students. ${ }^{17}$

One of the most cost-effective means of preventing the development of CVD among adults is the cessation of tobacco use. It is worth focusing on smoking prevention and cessation during adolescence because of the cost savings associated with smoking cessation and because the costs of quit services are relatively low. ${ }^{7}$ According to the SCORE risk chart, the 10-year risk of fatal CVD among smokers is approximately twice as high as among nonsmokers. ${ }^{3}$ In the European Union at the beginning of the $21^{\text {st }}$ century, the habit of smoking was observed in $39.5 \%$ of men and in $30.1 \%$ of women aged $20-44$; in Poland it was $46 \%$ and $31 \%$, respectively. ${ }^{20}$ In a comparison of university students from 23 countries, the lowest percentage of male current smokers was in Thailand (14\%) and South Africa (15\%), while the highest was in Portugal (47\%), Greece and Korea (both 44\%). ${ }^{21}$ Among female university students, the lowest percentage of current smokers was in Thailand (2\%), South Africa and Korea (both $4 \%$ ), while the highest was in Bulgaria and Spain (both 46\%), Greece and Portugal (both 42\%). Based on the research of Steptoe et al., there were $26 \%$ of men and women who were current smokers in Poland..$^{21}$ In this study, slightly fewer pharmacy students were current smokers compared to those from earlier years and compared to medical students from Wrocław. ${ }^{13,22}$ More current and former smokers were found among students from Lublin than from among the study group from Wrocław (men: $48 \%$ vs. $36.6 \%$; women: $34.2 \%$ vs $19.4 \%) .{ }^{15} 34.4 \%$ of male Lebanese students were current smokers and 9.4\% were ex-smokers, as well as $27.2 \%$ and $5.6 \%$, respectively, of female smokers and ex-smokers. ${ }^{18}$ Among university students from Sweden, $20 \%$ of women and $24 \%$ of men smoked. $^{23}$

Physical inactivity is indicated as one of the risk factors for CVD. ${ }^{1,3,7}$ Increased physical activity helps in maintaining proper body weight, controlling blood pressure, preventing and treating lipid disorders, and improving glycemic and insulin sensitivity. ${ }^{1,7}$ In the comparison conducted on university students from 23 countries, inactivity during leisure time was observed in $44 \%$ of students in developing countries, in $42 \%$ of students in the Pacific Asian region, in 39\% of those in the Mediterranean region, in 30\% of those in Central and Eastern Europe and in 23\% in the United States and Northwestern Europe. ${ }^{24}$ The highest age-adjusted prevalence of physical inactivity among women was observed in Portugal, South Africa, Korea and Venezuela, and among men in Portugal, South Africa, Romania and Venezuela. ${ }^{24}$ Low physical activity was declared more often by pharmacy students in the years 1998-2003 than in the present study (men: $42.9 \%$ vs $31.9 \%$; women: $55.1 \%$ vs $41.9 \%) .{ }^{13}$ Other results, outside of this study, were obtained from students in Lublin and Warszawa, where 
only $5.8 \%$ of the respondents declared a low level of physical activity and $72.1 \%$ declared a medium level. ${ }^{25}$ In the group of students from Sweden, 29\% of men and women did not declare regular exercise, while $40 \%$ and $30 \%$, respectively, declared a low level of exercise. ${ }^{23}$

Low intake of fruits and vegetables is one of the components of an unhealthy diet, which may increase the risk of CVD development., ${ }^{1,3}$ According to the "European Guidelines on cardiovascular disease prevention in clinical practice" it is recommended to consume at least $200 \mathrm{~g}$ of vegetables (2-3 servings) daily as well as $200 \mathrm{~g}$ of fruit (2-3 servings). ${ }^{3}$ The majority of the study group did not eat a sufficient amount of these foods. The average fruit intake among male pharmacy students from Wrocław between 2005 and 2007 was 100.2 g/day and 115.9 g/day among women. ${ }^{26}$ The average vegetable intake was $127.7 \mathrm{~g} /$ day and $124 \mathrm{~g} /$ day, respectively. ${ }^{26}$ In the WOBASZ study, the average fruit intake among men aged 20-34 years was $163.9 \mathrm{~g} /$ day and $196.8 \mathrm{~g} /$ day among women, while vegetable intake amounted to $222.2 \mathrm{~g}$ and $185.5 \mathrm{~g} /$ day, respectively. ${ }^{16}$ In the study of Ślusarska et al., consumption of fresh fruits and vegetables at least twice a day was declared by $44.2 \%$ of the respondents. ${ }^{25}$ Only $16.3 \%$ of the students from Warszawa and Lublin ate these foods at least 3 times a day. ${ }^{25}$ Among Lebanese university students, $29.2 \%$ of men declared daily consumption of fruit and vegetables and $25.8 \%$ and $31.5 \%$ of women for fruits and vegetables, respectively. ${ }^{18}$

\section{Conclusions}

In conclusion, the risk factors for cardiovascular diseases observed in this study were mainly associated with lifestyle factors, such as low physical activity, insufficient consumption of fruit and vegetables and tobacco use. A higher prevalence of certain cardiovascular risk factors was found more often among men than among women: excessive weight and obesity, abdominal obesity, hypertension, insufficient consumption of fruits and vegetables and smoking. The authors suggested that more attention should be paid to maintaining proper body weight. Physical activity should be promoted among students in view of its beneficial impact on body weight and blood pressure.

The excessive body weight, hypertension, low physical activity, smoking and low fruit and vegetable consumption found in a significant percentage of the study group may contribute to the future development of cardiovascular diseases in these individuals.

The authors concluded that although the study group consisted of young people, there was a high prevalence of cardiovascular risk factors, especially among men, and therefore preventive actions which promote proper nutrition, physical activity and smoking cessation should be implemented for the students.

\section{References}

1. Mendis S, Puska P, Norrving B, eds. Global atlas on cardiovascular disease prevention and control. World Health Organization, Geneva. 2011.

2. Lozano R, Naghavi M, Foreman K, et al. Global and regional mortality from 235 causes of death for 20 age groups in 1990 and 2010: A systematic analysis for the Global Burden of Disease Study 2010. Lancet. 2012;380:2095-2128.

3. Perk J, De Backer G, Gohlke H, et al. European Guidelines on cardiovascular disease prevention in clinical practice (version 2012). The Fifth Joint Task Force of the European Society of Cardiology and Other Societies on Cardiovascular Disease Prevention in Clinical Practice (constituted by representatives of nine societies and by invited experts). Eur Heart J. 2012;33:1635-1701.

4. Biro FM, Wien M. Childhood obesity and adult morbidities. Am J Clin Nutr. 2010;91:1499S-1505S.

5. Juonala M, Magnussen CG, Berenson GS, et al. Childhood adiposity, adult adiposity, and cardiovascular risk factors. $N$ Engl J Med. 2011;365:1876-1885.

6. Raitakari OT, Juonala M, Kähönen $M$, et al. Cardiovascular risk factors in childhood and carotid artery intima-media thickness in adulthood: The cardiovascular risk in young Finns study. JAMA. 2003;290:2277-2283.

7. Prevention of adult cardiovascular disease among adolescents: Focusing on risk factor reduction. National Institute for Health Care Management Foundation, Washington. 2008.

8. Obesity: Preventing and managing the global epidemic. Report of a WHO Consultation. World Health Organization, Geneva. 2000 (WHO Technical Report Series, No. 894).

9. Gianluca I. Obesity and Cardiovascular Disease, Oxford University Press, 2009.

10. Alberti KGMM, Eckel RH, Grundy SM, et al. Harmonizing the Metabolic Syndrome. A Joint Interim Statement of the International Diabetes Federation Task Force on Epidemiology and Prevention; National Heart, Lung, and Blood Institute; American Heart Association; World Heart Federation; International Atherosclerosis Society; and International Association for the Study of Obesity. Circulation. 2009;120:1640-1645.

11. Widecka K, Grodzicki T, Narkiewicz K, Tykarski A, Dziwura J. Rules of conduct in hypertension - 2011. The guidelines of the Polish Society of Hypertension. Arterial Hypertension. 2011;15:55-82.

12. Srinivasan SR, Bao W, Wattigney WA, Berenson GS. Adolescent overweight is associated with adult overweight and related multiple cardiovascular risk factors: The Bogalusa Heart Study. Metabolism. 1996;45:235-240.

13. Ilow R, Regulska-llow B, Różańska D. Prevalence of risk factors for cardiovascular diseases among university students in Wroclaw. Med Og Nauk Zdr. 2012;18:442-447.

14. Kardjalik K, Bryła M, Maniecka-Bryła I. Nutrition-related health behaviors and prevalence of overweight and obesity in a group of university students. Probl Hig Epidemiol. 2012;93:71-79.

15. Wołos J, Tarach JS, Klatka M. The incidence of obesity and some cardiovascular risk factors in a group of university students in Lublin. Endokrynol Otyl Zab Przem Mat. 2009;5:66-72.

16. Broda G, Rywik S, Kurjata P, eds. National Multicenter Health Survey in Poland Project WOBASZ. Health status of the Polish population aged 20-74 years in the period 2003-2005. Part I - National Sample. Instytut Kardiologii, Biblioteka Kardiologiczna 90, Warszawa, 2005.

17. Bertsias G, Mammas I, Linardakis M, Kafatos A. Overweight and obesity in relation to cardiovascular disease risk factors among medical students in Crete, Greece. BMC Public Health. 2003;3:3. doi:10.1186/1471-2458-3-3.

18. Yahia N, Achkar A, Abdallah A, Rizk S. Eating habits and obesity among Lebanese university students. Nutr J. 2008;7:32. doi:10.1186/1475-2891-7-32.

19. Krzych $\measuredangle$, Kowalska M, Zejda JE. Risk factors and the prevalence of hypertension in young adults. Arterial Hypertension. 2006;10: 136-141.

20. Zatoński W, Przewoźniak K, Sulkowska U, West R, Wojtyła A. Tobacco smoking in countries of the European Union. Ann Agric Environ Med. 2012;19:181-192. 
21. Steptoe A, Wardle J, Cui W, et al. An international comparison of tobacco smoking, beliefs and risk awareness in university students from 23 countries. Addiction. 2002;97:1561-1571.

22. Janik-Koncewicz K, Zatoński T, Połtyn-Zaradna K, et al. An attempt to assess knowledge about tobacco dependence among students at the Medical University in Wroclaw. Ann Agric Environ Med. 2012;19:345-349.

23. von Bothmer MIK, Fridlund B. Gender differences in health habits and in motivation for a healthy lifestyle among Swedish university students. Nurs Health Sci. 2005;7:107-118.

24. Haase A, Steptoe A, Sallis JF, Wardle J. Leisure-time physical activity in university students from 23 countries: Associations with health beliefs, risk awareness, and national economic development. Prev Med. 2004;39:182-190.

25. Ślusarska B, Kulik TB, Piasecka H, Pacian A. Knowledge of cardiovascular risk factors and health promoting behaviours among students of medicine. Med Og Nauk Zdr. 2012;18:19-26.

26. Ilow R, Regulska-llow B, Różańska D, Tangermann S, Grajeta H. Assessment of total antioxidant capacity of selected food products consumed by the Medical University students from Wrocław in 2005-2007. Bromat Chem Toksykol. 2012;45:995-1000. 